\title{
Efficacy analysis of self-help position therapy after holmium laser lithotripsy via flexible ureteroscopy
}

Jie Yang ${ }^{1 \dagger}$, Rong-zhen Tao ${ }^{1,3+}$, Pei Lu ${ }^{1 \dagger}$, Meng-xing Chen ${ }^{2}$, Xin-kun Huang ${ }^{3}$, Ke-liang Chen ${ }^{1}$, Ying-heng Huang ${ }^{2}$, Xiao-rong He${ }^{2}$, Li-di Wan², Jing Wang ${ }^{2}$, Xin Tang ${ }^{2}$ and Wei Zhang ${ }^{1 *}$

\begin{abstract}
Background: To observe the efficacy of self-help position therapy (SHPT) after holmium laser lithotripsy via flexible ureteroscopy (FURS).

Methods: From January 2010 to November 2015, 736 nephrolithiasis patients who had received FURS lithotripsy were analyzed retrospectively. In position group, 220 cases accepted SHPT after lithotripsies, and 428 cases as control, coming from another independent inpatient area in the same center. The stone-free status (SFS) between two groups were compared at the 2nd, 4th and 12 th week ends by X-ray examinations.

Results: The preoperative incidence of hydronephrosis ( $25.9 \%$ vs. $18.0 \%, p=0.018)$ or lower calyceal seeper (33.6\% vs. $24.3 \%, p=0.012$ ) and the proportion of patients with $>2.0 \mathrm{~cm}$ stones (33.6\% vs. $24.3 \%, p=0.003$ ) were all significantly higher in position group than in control group. There were no substantial difference between two groups in age, BMl, gender and medical histories. In postoperative followup, the incidence of hydronephrosis in position group was significantly lower than in control group (9.5\% vs. $15.7 \%, p=0.032)$ after removing double-J stents. In position group, the SFS of the 2 nd week end ( $60.9 \%$ vs. $47.2 \%, p=0.001)$, the 4 th week end (74.1\% vs. 62. $8 \%, p=0.004)$ and the 12 th week end $(86.9 \%$ vs. $79.4 \%, p=0.021)$ were all significantly higher than those in control group.

Conclusions: SHPT after holmium laser lithotripsy via FURS may increase postoperative SFS, accelerate stone fragment clearance, and decrease the incidence of hydronephrosis after removal of double-J stents. The therapy does not require professional assistance and is economical, simple, and effective.
\end{abstract}

Keywords: Flexible ureteroscopy, Holmium laser lithotripsy, Self-help, Position therapy, Hydronephrosis

\section{Background}

Nephrolithiasis is one of the most frequently encountered diseases in urology practice. It varies in occurrence globally [1]. In 2011, the incidence was $1-5 \%$ in China and $2-19 \%$ in Western countries [2-4]. Minimally invasive procedures are being used more often for the treatment of nephrolithiasis. Flexible ureteroscopy (FURS) with holmium laser lithotripsy is the most popular and mature technology for small- and mid-size renal stones

\footnotetext{
* Correspondence: trz1891597@126.com

${ }^{\dagger}$ Equal contributors

'Department of Urology, First Affiliated Hospital of Nanjing Medical

University, Nanjing 210029, Jiangsu, China

Full list of author information is available at the end of the article
}

$(\leq 2.5 \mathrm{~cm})$. The documented advantages of FURS include minimal trauma, few complications, and rapid recuperation [5-7]. However, postoperative stone residue and fusion of drainable fragments $(\leq 4 \mathrm{~mm})$ are still intractable problems in clinical practice $[8,9]$. Hyams et al. reported 120 cases undergoing FURS with holmium laser lithotripsy for renal stones $2-3 \mathrm{~cm}$ in size (mean 2 . $4 \mathrm{~cm})$. During a 2-month follow-up, $56(47 \%)$ patients were truly stone free, $20(19 \%)$ had a residual burden of $<2 \mathrm{~mm}$, and $24(17 \%)$ had a residual burden of $2-4 \mathrm{~mm}$ [10]. Residual lower pole fragments $<2 \mathrm{~mm}$ in diameter can still be difficult to clear from the renal collecting system due to gravity and anatomy (the length and width

(c) The Author(s). 2018 Open Access This article is distributed under the terms of the Creative Commons Attribution 4.0 International License (http://creativecommons.org/licenses/by/4.0/), which permits unrestricted use, distribution, and 
of the lower caliceal infundibulum and the relative angle between the lower calyx and renal pelvis) [11-13].

To address this problem, the inversion-table treatment has been introduced for clinical use $[14,15]$. It is a complicated operation requiring professional assistance and is expensive. These drawbacks have hindered its clinical application. The treatment is often unsuitable for patients with severe heart or brain vessel diseases.

Our long-term experience has indicated the value of selfhelp position therapy (SHPT) to increase the passive egress of stone fragments $\leq 4 \mathrm{~mm}$ in size. SHPT does not require professional assistance and appears to be safe, simple, effective, and suitable for most patients. To investigate its exact efficacy, data of 736 consecutive patients with nephrolithiasis who received holmium laser lithotripsy via FURS from January 2010 to November 2015 were retrospectively analyzed. The patients were divided into a position group and a control group to compare stone-expelling efficacy by postoperative stone free status (SFS) and stone expulsion time.

\section{Methods}

\section{Patients}

From January 2010 to November 2015, holmium laser lithotripsies via FURS were performed on a consecutive series of 736 adult patients with kidney stones by the same surgical team in our center. Applying strict inclusion criteria, 648 patients were ultimately included (Fig. 1). Outpatient and inpatient records for each enrollee were reviewed, which included admission and discharge records, laboratory examination reports, radiological images, operative records, and stone analysis reports. Information was collected in telephone or faceto-face interviews using a uniform questionnaire that consisted of general characteristics including population and practices between institutions, personal medical history including lithotripsy and double-J stent placement, lifestyle, occupational history, dietary habits, and family history. Consent for participation was obtained from all participants. This study was approved by the Ethic Committee of First Affiliated Hospital of Nanjing Medical University.

\section{Perioperative and surgical procedure}

All enrollees received a preoperative plain abdominal radiograph of the kidneys, ureters, and bladder (KUB) and unenhanced computed tomography (CT) to assess hydronephrosis and the size, location, and number of stones. The same imaging regimen was used for all

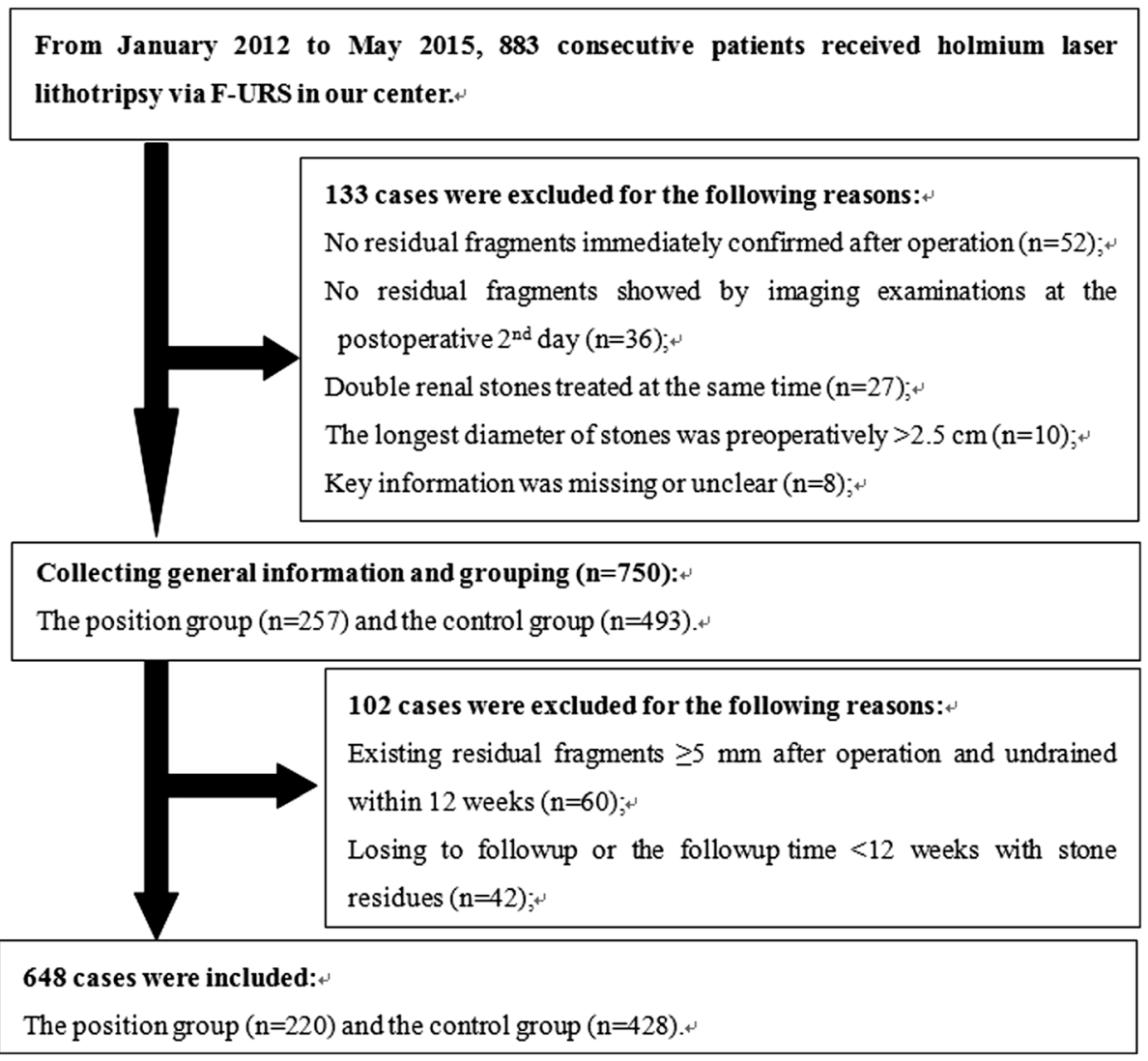

Fig. 1 Flowchart for case selection 
patients. Stone size was determined by measuring the longest diameter on the preoperative radiologic images. In the case of multiple stones, the sum of the longest diameters of stones was used [16].

Patients were placed in a lithotomy position after general anesthesia, then a semirigid ureteroscope (8-9.8 F; Richard Wolf GmbH, Knittlingen, Germany) was retrogradely inserted into the upper urinary tract with the assistance of a Zebra guidewire (Cook Medical, Bloomington, IN, USA) to check the ureter and simplify the placement of a $12 / 14 \mathrm{~F}$ ureteral access sheath (UAS; Cook Medical, Limerick, Ireland). A 7.5F fiberoptic FURS (P5; Olympus, Tokyo, Japan) was inserted into the renal pelvis via the UAS to search and fragment stones $(\leq 2 \mathrm{~mm})$. Fragmentation was done using a 200 um holmium laser fiber at an energy setting of 12-20 W based on the visually determined hardness of stones. Routinely, a 4.7F double-J stent (Bard Peripheral Vascular, Tempe, AZ, USA) was placed after lithotripsy. If the UAS could not be positioned due to ureter straitness, a 6F double-J stent (Bard Peripheral Vascular) was implanted for 2 weeks before lithotripsy.

A kidney, ureter, and bladder (KUB) examination was done on postoperative day 1 . If residual fragments were found, patients in the position group were instructed to assume the SHPT, in which they adopted a contralateral head-down tilt position of at least $45^{\circ}$ and maintained the position for $5 \mathrm{~min}$ (Fig. 2). The patients were instructed to perform the SHPT once a day during their hospitalization and for 12 weeks following discharge depending on the expelling efficacy of the stone. The control group comprised patients in another independent inpatient area of the same center. They were not given any information regarding position therapy for expelling of fragments. Both groups were suggested to receive medical expulsive therapy consisting of tamsulosin twice a day [17] and hydration with about $2 \mathrm{~L}$ of water each day. Implanted double-J stents were removed at postoperative 1-3 months on the basis of the stoneexpelling efficacy.

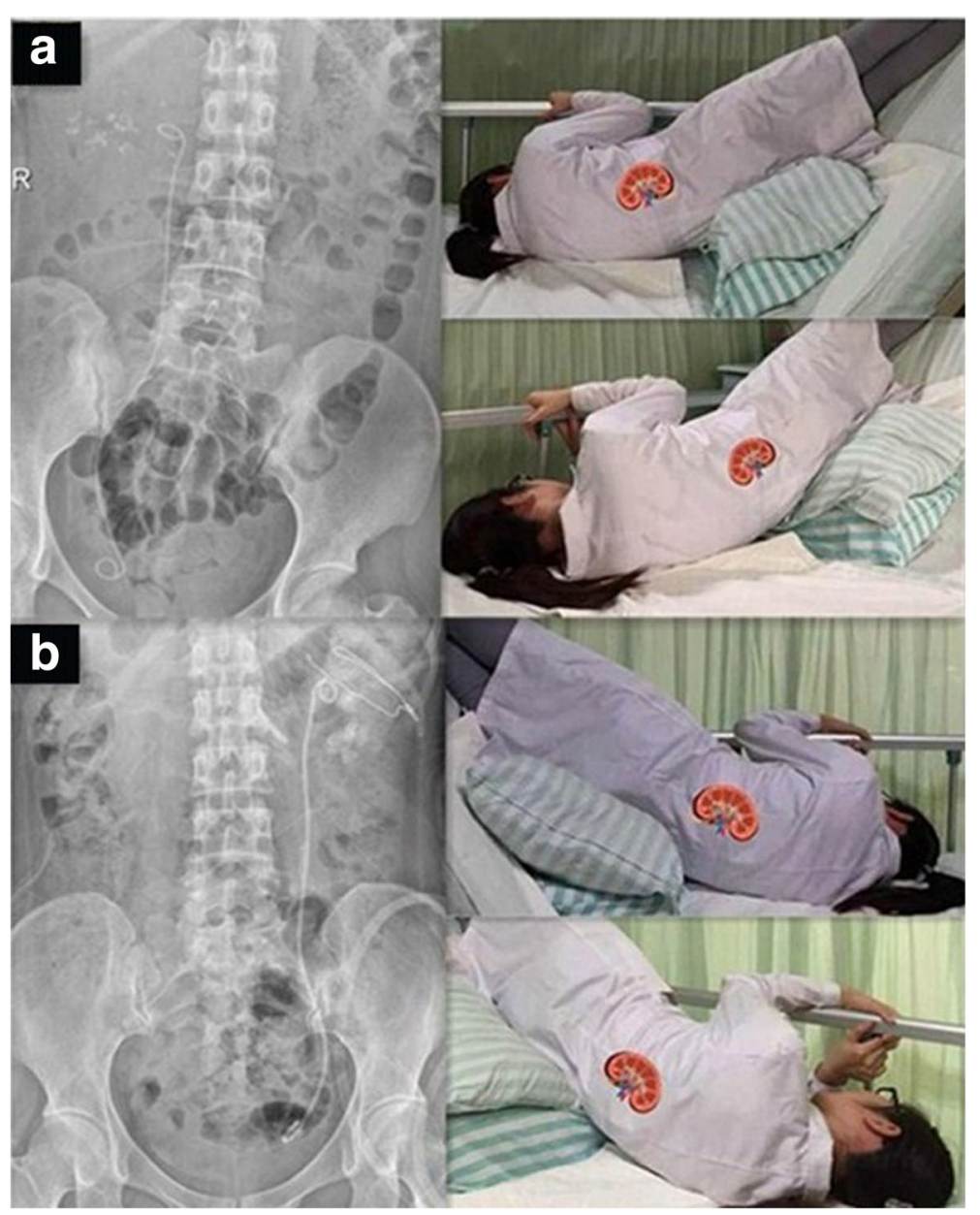

Fig. 2 The self-help position therapy (SHPT) after lithotripsies. a SHPT for right renal residual fragments; b SHPT for left renal residual fragments 
Follow-up

Follow-up determinations included complete blood count, routine urinalysis, serum creatinine, and KUB examination. The determinations were done at postoperative week 2, 4, and 12 (Additional file 1: Figure S1). SFS was defined as no radiological evidence of stone or the presence of $\leq 2 \mathrm{~mm}$ asymptomatic fragments in the urinary tract [18-20].

\section{Statistical analyses}

SPSS v.16.0 for Windows (IBM Corp., Armonk, NY, USA) was used to perform statistical analyses. Continuous variables are presented as mean \pm standard deviation. Patient demographics, follow-up time, and surgical outcomes between the two groups were compared using independent sample $t$ test. The chi-squared test was used to compare other preoperative and postoperative clinical characteristics between the two groups. A $p$-value $<0.05$ was considered significant.

\section{Results}

\section{Demographics and preoperative clinical characteristics}

The mean age at diagnosis in the position and control group was 46.4 and 44.1 years, respectively. The incidence of preoperative hydronephrosis $(25.9 \%$ vs. $18.0 \%, p=0.018)$ and lower calyceal seeper (33.6\% vs. $24.3 \%, p=0.012)$, and the proportion of patients with stones $>2.0 \mathrm{~cm}$ in size (33. $6 \%$ vs. $24.3 \%, p=0.003$ ) were significantly higher in the position group than in the control group. The percentage of patients with stones that were exclusively located in the lower calyx was slightly and non-significantly higher in the position group than in the control group (47.3\% vs. $37.6 \%$, $p=0.164)$. There was no substantial difference between two groups in mean age, body mass index, gender, history of hypertension and diabetes, history of preoperative extracorporeal shock-wave lithotomy (ESWL), and nephrolithiasis surgery, preoperative renal function, and history of double-J stents placement (all $p>0.05$ ) (Table 1 ).

\section{Surgical outcomes and postoperative clinical characteristics}

In postoperative follow-up, the incidence of hydronephrosis in the position group was significantly lower than in the control group $(9.5 \%$ vs. $15.7 \%, p=0.032)$. SFS in the position group was significantly higher than in the control group at week $2(60.9 \%$ vs. $47.2 \%, p=0.001)$, week 4 (74. $1 \%$ vs. $62.8 \%, p=0.004)$, and week 12 (86.9\% vs. 79 . $4 \%, p=0.021)$. However, there was no statistical significance between the groups concerning operative time, HGB decrease, hospital stay, postoperative anal aerofluxus time, stone composition, and postoperative renal function (all $p>0.05$ ) (Table 2).
Table 1 Comparisons of patients' demographics and preoperative clinical characteristics between the two groups

\begin{tabular}{llll}
\hline $\begin{array}{l}\text { Variables, mean } \pm \\
\text { SD or } \mathrm{n}(\%)\end{array}$ & $\begin{array}{l}\text { Position group } \\
(n=220)\end{array}$ & $\begin{array}{l}\text { Control group } \\
(n=428)\end{array}$ & $P$ value \\
\hline Age, year & $46.4 \pm 5.3$ & $44.1 \pm 3.7$ & 0.782 \\
BMl, kg/m2 & $22.1 \pm 2.7$ & $23.3 \pm 1.5$ & 0.635 \\
$\begin{array}{l}\text { Gender } \\
\quad \text { Male }\end{array}$ & $123(55.9)$ & $222(51.9)$ & - \\
$\quad$ Female & $97(44.1)$ & $206(48.1)$ & 0.329 \\
$\begin{array}{l}\text { Hypertension history } \\
\quad \text { No }\end{array}$ & $160(72.7)$ & $328(76.6)$ & - \\
$\quad$ Yes & $60(27.3)$ & $100(23.4)$ & 0.275 \\
Diabetes history & & & \\
$\quad$ No & $201(91.4)$ & $383(89.5)$ & - \\
$\quad$ Yes & $19(8.6)$ & $45(10.5)$ & 0.448
\end{tabular}

Stone size, $\mathrm{cm}$

$\begin{array}{llll}<1.0 \mathrm{~cm} & 37(16.8) & 106(24.8) & -\end{array}$

$\begin{array}{llll}1.0-2.0 \mathrm{~cm} & 109(49.6) & 218(50.9) & 0.108\end{array}$

$2.0-2.5 \mathrm{~cm} \quad 74(33.6) \quad 104(24.3) \quad 0.003^{* *}$

Stone locations

$\begin{array}{llll}\text { Pelvis or upper calyx } & 83(37.7) & 166(38.8) & - \\ \text { Middle calyx } & 33(15.0) & 101(23.6) & 0.077 \\ \text { Lower calyx } & 104(47.3) & 161(37.6) & 0.164\end{array}$

ESWL history

$\begin{array}{llll}\text { No } & 115(52.3) & 245(57.2) & - \\ \text { Yes } & 105(47.7) & 183(42.8) & 0.228\end{array}$

Nephrolithiasis operation histories ${ }^{\mathrm{a}}$

$\begin{array}{llll}\text { No } & 164(74.5) & 297(69.4) & - \\ \text { Yes } & 56(25.5) & 131(30.7) & 0.170\end{array}$

Preoperative hydronephrosis

$\begin{array}{llll}\text { No } & 163(74.1) & 351(82.0) & - \\ \text { Yes } & 57(25.9) & 77(18.0) & 0.018^{*}\end{array}$

Preoperative lower calyceal seeper

$\begin{array}{llll}\text { No } & 146(66.4) & 324(75.7) & \\ \text { Yes } & 74(33.6) & 104(24.3) & 0.012^{*} \\ \text { Preoperative renal function } & & \\ \text { Normal } & 199(90.5) & 394(92.0) & - \\ \text { Abnormal } & 21(9.5) & 34(8.0) & 0.488\end{array}$

Double-J stents placed histories

\begin{tabular}{llll} 
No & $140(63.6)$ & $288(67.3)$ & - \\
Yes & $80(36.4)$ & $140(32.7)$ & 0.352 \\
\hline
\end{tabular}

$B M I$ body mass index, $S D$ standard deviation, ESWL extracorporeal shock wave lithotripsy

${ }^{a}$ Nephrolithiasis operation histories include flexible ureteroscope lithotripsy, percutaneous nephrolithotomy or nephrolithotomy ${ }^{*} p<0.05,{ }^{* *} p<0.01$ 
Table 2 Comparisons of surgical outcomes and postoperative clinical characteristics between two groups

\begin{tabular}{|c|c|c|c|}
\hline $\begin{array}{l}\text { Variables, mean } \pm \\
\text { SD or } n(\%)\end{array}$ & $\begin{array}{l}\text { Position group } \\
(n=220)\end{array}$ & $\begin{array}{l}\text { Control group } \\
(n=428)\end{array}$ & $P$ value \\
\hline Follow-up, month & $3.3 \pm 0.4$ & $3.6 \pm 0.4$ & 0.417 \\
\hline \multicolumn{4}{|l|}{ Surgical outcomes } \\
\hline operative time, hour & $1.7 \pm 0.6$ & $1.5 \pm 0.5$ & 0.243 \\
\hline HGB decrease (g/L) & $4.9 \pm 3.4$ & $5.3 \pm 3.7$ & 0.915 \\
\hline Hospital stay, day & $1.8 \pm 0.4$ & $1.9 \pm 0.5$ & 0.973 \\
\hline $\begin{array}{l}\text { Postoperative anal } \\
\text { aerofluxus time, day }\end{array}$ & $1.2 \pm 0.3$ & $1.1 \pm 0.4$ & 0.853 \\
\hline \multicolumn{4}{|l|}{ Stone compositions } \\
\hline Calcium oxalate & $127(57.7)$ & $257(60.0)$ & - \\
\hline Struvite & $51(23.2)$ & $84(19.6)$ & 0.322 \\
\hline Calcium phosphate & $42(19.1)$ & $87(20.4)$ & 0.914 \\
\hline \multicolumn{4}{|c|}{ Postoperative renal function } \\
\hline Normal & $209(95.1)$ & $410(95.8)$ & - \\
\hline Abnormal & $11(4.9)$ & $18(4.2)$ & 0.643 \\
\hline \multicolumn{4}{|c|}{ Postoperative hydronephrosis } \\
\hline No & $199(90.5)$ & $361(84.3)$ & - \\
\hline Yes & $21(9.5)$ & $67(15.7)$ & $0.032^{*}$ \\
\hline
\end{tabular}

SFS at the 2nd week end

$\begin{array}{llll}\text { No } & 86(39.1) & 226(52.8) & - \\ \text { Yes } & 134(60.9) & 202(47.2) & 0.001^{* *}\end{array}$

SFS at the 4th week end

$\begin{array}{llll}\text { No } & 57(25.9) & 159(37.1) & \\ \text { Yes } & 163(74.1) & 269(62.9) & 0.004^{* *}\end{array}$

SFS at the 12th week end

\begin{tabular}{llll} 
No & $29(13.1)$ & $88(20.6)$ & \\
Yes & $191(86.9)$ & $340(79.4)$ & $0.021^{*}$ \\
\hline
\end{tabular}

$S D$ standard deviation, $H G B$ hemoglobin, SFS stone free status ${ }^{*} p<0.05,{ }^{* *} p<0.01$

\section{Discussion}

The clinical application of FURS was first reported in 1964 [21]. Since then, the equipment and optical imaging system have evolved quickly. FURS with holmium laser, which allows retrograde access to any calices of the renal collecting system, has increasingly become the first-line therapy for renal calculi, especially for patients with blood coagulation dysfunction, renal insufficiency, obesity, isolated kidney, or undergoing failed lithotripsies of ESWL or percutaneous nephrolithotomy (PCNL) [22-24].

The SFR is 70-90\% after holmium laser lithotripsy using FURS at 3 months postoperatively $[8,9]$. However, residual stone and gravel fusion remain troublesome problems. Residual calculi $\leq 2 \mathrm{~mm}$ in size in the absence of obstruction or infection are defined as clinically insignificant residual fragments $[19,20]$. Although these fragments are usually clinically insignificant, they might enlarge and lead to infection or obstruction of the urinary tract. In a study of 384 patients undergoing FURS, clinically insignificant residual fragments were present in 44 (11.5\%) patients by abdominal CT from postoperative 3 weeks to 3 months [25]. Among them, 15 patients showed symptoms resulting from the enlargement or fusion of residual gravels. Therefore, promoting the discharge of clinically insignificant residual fragments from the urinary tract as soon as possible is prudent following lithotripsy.

Methods promoting the elimination of residual gravel and increasing postoperative SFR include drug-mediated dissolution of stones or stone discharge by movement or an inverted position. Position therapy has proven especially effective for lower pole residual gravel. Lower calices are the lowest parts of the renal collecting system, and are usually $2-3 \mathrm{~cm}$ distant from the calyceal bottom to the pelvic openings [26]. The distance will increase significantly with seeper in lower calices. Therefore, the lower pole residual stones are commonly difficult to expel with urine in the upright position due to the gravity and postoperative hydronephrosis, even if they have broken into small $(<2 \mathrm{~mm})$ pieces. The effectiveness of inversion positioning prompted our center to initiate SHPT after holmium laser lithotripsy via FURS beginning in 2010 (Fig. 2), particularly for patients with preoperative hydronephrosis (Table 1).

Postoperative position therapy is also imperative for patients with large kidney stones $(\leq 4 \mathrm{~mm})$ after lithotripsy. If the stone pieces are not excreted during the first 3 months postoperatively, they will tend to fuse or growth, which can result in obstruction or infection in the urinary tract. Presently, although the preoperative rates of hydronephrosis and lower calyceal seeper were significantly higher in the position group than in the control group, the incidence of hydronephrosis was conspicuously lower in the position group after removal of double-J stents (Table 2). This highlights the importance of the timely expulsion of residual stones.

The discharge efficacy of residual stones with the assistance of inversion-table treatment has been confirmed. Pace et al. reported that a 60-degree tilt inversion combined with mechanical percussion effectively renders residual lower caliceal region stone-free, with a substantially higher SFR than that of the control group (40\% vs. $3 \%, p<0.01$ ) 3 months after ESWL [14]. Another study also showed that inversion-table treatment group had higher SFR than control group in patients with lower calyceal stones undergoing FURS lithotripsy ( $97.4 \%$ vs. $81.8 \%, p<0.05)$ [15]. However, the exact effect of an economic and easy-to-do SHPT has not been described. To provide clarity, the present retrospective study was undertaken to analyze the effect of SHPT in a consecutive cohort at our hospital. The 
position group still had a significantly higher SFS than the control group, although the preoperative incidence of hydronephrosis or lower calyceal seeper and the proportion of patients with stones $>2.0 \mathrm{~cm}$ in size were both higher in position group. Especially, at postoperative week 2, the difference of SFS between the two groups was most significant ( $60.9 \%$ vs. $47.2 \%, p=0.001)$. Thereafter the difference gradually lessening, but it remained statistically significant at week $12(86.9 \%$ vs. $79.4 \%, p=0.021$ ) (Table 2). This indicates that inversion exceeding 45-degrees in a head-down position can speed up the expulsion of residual stones and compensate for the deficiency of gravel deposition in lower calices after renal stones are broken into $<2 \mathrm{~mm}$ pieces (the standard of CIRF) using FURS lithotripsy.

Our study chronicles the good curative effect of SHPT after holmium laser lithotripsy via FURS. However, therapeutic planning still needs to be individualized and optimized with respect to start time, frequency, duration, and inversion angles.

The study also has some limitations. It is a retrospective study, lacking the characteristics of random grouping and high homogeneity of patients between groups. Furthermore, we did not compare SHPT with inversiontable treatment in the effectiveness of expelling residual stones. Finally, the study is a single center study with relatively small sample size. There is the possibility of sampling error.

\section{Conclusions}

SHPT after holmium laser lithotripsy via FURS may increase postoperative SFS, accelerate stone fragment clearance, and decrease the incidence of hydronephrosis after removal of double-J stents. The therapy does not require professional assistance and is economical, simple, and effective. A prospective randomized controlled trial should be performed.

\section{Additional file}

Additional file 1: Figure S1. Abdominal plain films monitor residual fragment expelling at the postoperative 1st day (A), at the postoperative 2nd week end (B), at the postoperative 4th week end (C), and at the postoperative 12th week end (D). (JPG $151 \mathrm{~kb}$ )

\section{Abbreviations \\ CIRF: Clinically insignificant residual fragments; CT: Computed tomography; ESWL: Extracorporeal shock-wave lithotomy; FURS: Flexible ureteroscopy; KUB: Kidneys, ureters and bladder; PCNL: Percutaneous nephrolithotomy; SFR: Stone-free rate; SFS: Stone free status; SHPT: Self-help position therapy}

\section{Acknowledgements}

$J Y$ and PL conceived and designed the study. JY and RZT drafted the manuscript. JY and RZT revised the manuscript. WZ provided technical help and writing assistance. All authors have read and approved the final version.

\section{Funding}

This study received no specific grant from any funding agency in the public, commercial or not-for-profit sectors.

\section{Availability of data and materials}

The data that support the findings of this study are available from the corresponding author on reasonable request.

\section{Authors' contributions}

$J Y$ and PL conceived and designed the study; YHH, XRH, LDW, XT and JW as corresponding researchers collected clinical information and interviewed patients in five medical teams; MXC and XKH organized and input the data; KLC checked and verified data input by MXC and XKH; RZT and WZ performed statistical analyses; JY and RZT drafted the manuscript; JY and RZT revised the manuscript. All authors have read and approved the final manuscript.

\section{Ethics approval and consent to participate}

This study has been approved by the Ethics Committee of First Affiliated Hospital of Nanjing Medical University [81171963]. The committee approved the requirement for verbal informed consent to be obtained from participants.

\section{Competing interests}

The authors declare that they have no competing interests.

\section{Publisher's Note}

Springer Nature remains neutral with regard to jurisdictional claims in published maps and institutional affiliations.

\section{Author details}

${ }^{1}$ Department of Urology, First Affiliated Hospital of Nanjing Medical University, Nanjing 210029, Jiangsu, China. ${ }^{2}$ First Clinical Medical College, Nanjing Medical University, Nanjing, Jiangsu, China. ${ }^{3}$ Department of Urology, The Affiliated Jiangning Hospital with Nanjing Medical University, Nanjing, Jiangsu, China.

Received: 10 June 2016 Accepted: 2 May 2018

Published online: 08 May 2018

References

1. Trinchieri A. Epidemiology of urolithiasis. Arch Ital Urol Androl. 1996;68:203-49.

2. Zeng $Q, H e ~ Y$. Age-specific prevalence of kidney stones in Chinese urban inhabitants. Urolithiasis. 2013:41(1):91-3.

3. Turk C, Knoll T, Petrik A, et al. Guidelines on Urolithiasis. European Association of Urology: Arnhem; 2013.

4. Na YQ, Ye ZQ, Sun ZY, et al. The guideline of Chinese Association of Urology. Chinese Association of Urology: Beijing; 2011. p. 209.

5. Xu C, Song RJ, Jiang MJ, Qin C, Wang XL, Zhang W. Flexible ureteroscopy with holmium laser lithotripsy: a new choice for intrarenal stone patients. Urol Int. 2015;94(1):93-8

6. Ding J, Xu D, Cao Q, et al. Comparing the efficacy of a multimodular flexible Ureteroscope with its conventional counterpart in the Management of Renal Stones. Urology. 2015;86(2):224-9.

7. Miernik A, Wilhelm K, Ardelt P, et al. Standardized flexible ureteroscopic technique to improve stone-free rates. Urology. 2012;80:1198-202.

8. Osman Y, Harraz AM, El-Nahas AR, et al. Clinically insignificant residual fragments: an acceptable term in the computed tomography era? Urology. 2013;81(4):723-6.

9. Delvecchio FC, Preminger GM. Management of residual stones. The Urol Clin North Am. 2000:27(2):347-54. 10778476

10. Hyams ES, Munver R, Bird VG, Uberoi J, Shah O. Flexible ureterorenoscopy and holmium laser lithotripsy for the management of renal stone burdens that measure 2 to $3 \mathrm{~cm}$ : a multi-institutional experience. J Endourol. 2010; 24(10):1583-8

11. Burr J, Ishii H, Simmonds N, Somani BK. Is flexible ureterorenoscopy and laser lithotripsy the new gold standard for lower pole renal stones when compared to shock wave lithotripsy: comparative outcomes from a university hospital over similar time period. Cent European J Urol. 2015; 68(2):183-6.

12. Kosar A, Ozturk A, Serel TA, et al. Effect of vibration massage therapy after extracorporeal shockwave lithotripsy in patients with lower caliceal stones. J Endourol. 1999;13:705 
13. Sampaio FJ, Aragao AH. Limitations of extracorporeal shockwave lithotripsy for lower caliceal stones: anatomic insight. J Endourol. 1994;8:241.

14. Pace KT, Tariq N, Dyer SJ, Weir MJ, RJ DAH. Mechanical percussion, inversion and diuresis for residual lower pole fragments after shock wave lithotripsy: a prospective, single blind, randomized controlled trial. J Urol. 2001;166(6): 2065-71.

15. Chiong E, Hwee ST, Kay LM, Liang S, Kamaraj R, Esuvaranathan K. Randomized controlled study of mechanical percussion, diuresis, and inversion therapy to assist passage of lower pole renal calculi after shock wave lithotripsy. Urology. 2005;65(6):1070-4.

16. Tiselius $\mathrm{H}-\mathrm{G}$, Andersson A. Stone burden in an average Swedish population of stone formers requiring active stone removal: how can the stone size be estimated in the clinical routine? Eur Urol. 2003;43:275-81.

17. Yilmaz E, Batislam E, Basar MM. The comparison and efficacy of 3 different alphal -adrenergic blockers for distal ureteral stones[J]. J Urol. 2005;173

18. Ghani KR, Wolf JS Jr. What is the stone-free rate following flexible ureteroscopy for kidney stones? Nat Rev Urol. 2015;12(7):363.

19. Dauw CA, Simeon L, Alruwaily AF, et al. Contemporary practice patterns of flexible Ureteroscopy for treating renal stones: results of a worldwide survey. J Endourol. 2015;29(11):1221-30.

20. Huang ZC, Fu FJ, Zhong ZH, et al. Flexible ureteroscopy and laser lithotripsy for bilateral multiple intrarenal stones: is this a valuable choice? Urology. 2012;80:800-4

21. Marshall VF. Fiber optics in urology. J Urol. 1964;91:110-4.

22. Wen CC, Nakada SY. Treatment selection and outcomes: renal calculi. Urol Clin North Am. 2007:34(3):409-19.

23. Breda A, Ogunyemi O, Leppert JT, Lam JS, Schulam PG. Flexible ureteroscopy and laser lithotripsy for single intrarenal stones $2 \mathrm{~cm}$ or greater-is this the new frontier? J Urol. 2008;179(3):981-4.

24. Xu G, Wen J, Li Z, et al. A comparative study to analyze the efficacy and safety of flexible ureteroscopy combined with holmium laser lithotripsy for residual calculi after percutaneous nephrolithotripsy. Int J Clin Exp Med. 2015;8(3):4501-7.

25. Ozgor F, Simsek A, Binbay M, et al. Clinically insignificant residual fragments after flexible ureterorenoscopy: medium-term follow-up results. Urolithiasis. 2014;42(6):533-8.

26. Wolf JS Jr. Is lower pole caliceal anatomy predictive of extracorporeal shock wave lithotripsy success for primary lower pole kidney stones? Int Braz J Urol. 2002;28(6):572-3.

\section{Ready to submit your research? Choose BMC and benefit from:}

- fast, convenient online submission

- thorough peer review by experienced researchers in your field

- rapid publication on acceptance

- support for research data, including large and complex data types

- gold Open Access which fosters wider collaboration and increased citations

- maximum visibility for your research: over $100 \mathrm{M}$ website views per year

At BMC, research is always in progress.

Learn more biomedcentral.com/submissions 